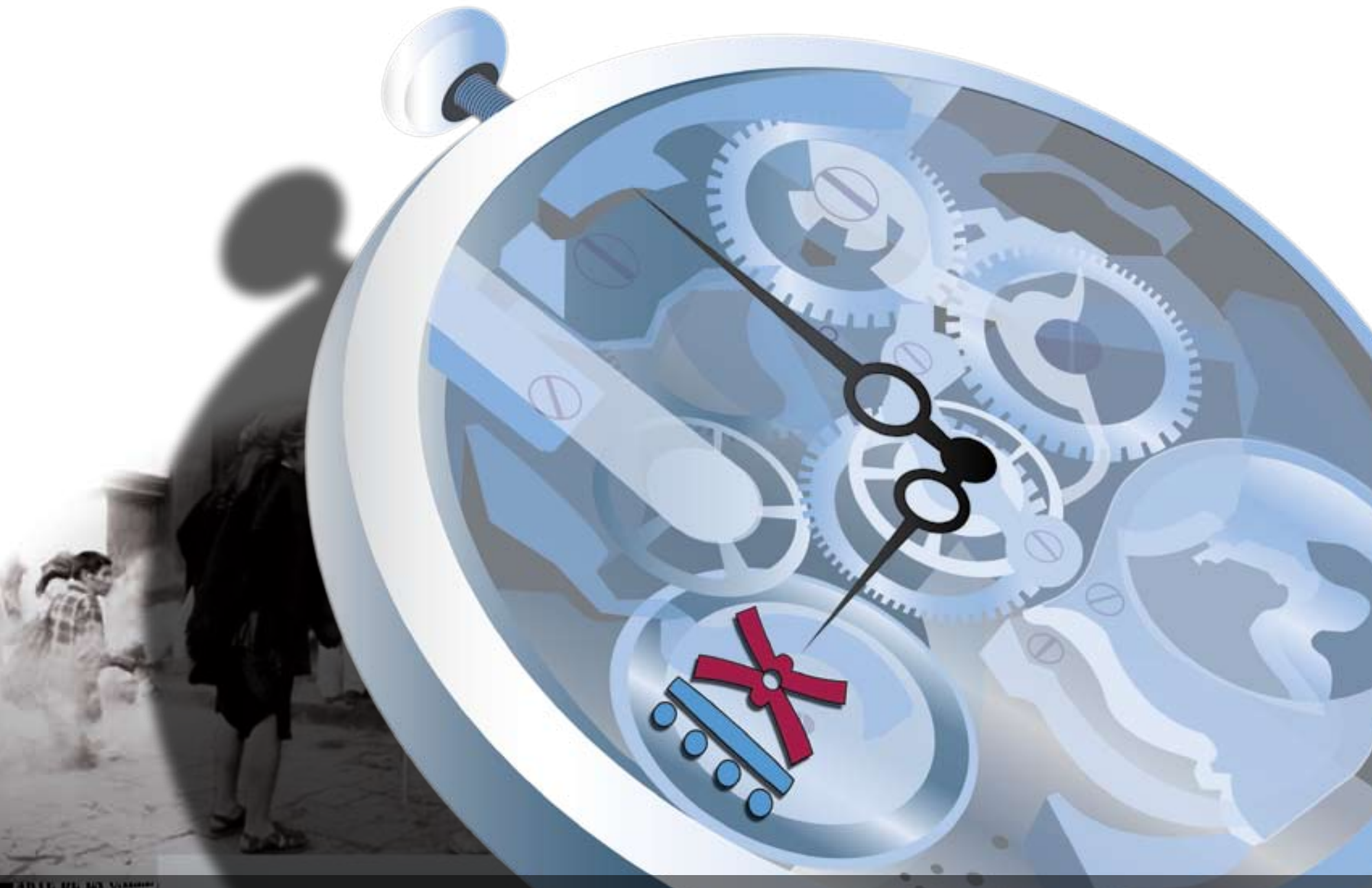

P $9^{\circ}$ C O N G R S O 2. CENTROAMERICANO DE HISTORIA Universidad de Costa Rica ISSN 1409-469X

Fecha de recepción: 15 de mayo 2008 Fecha de aceptación: 30 de mayo 2008

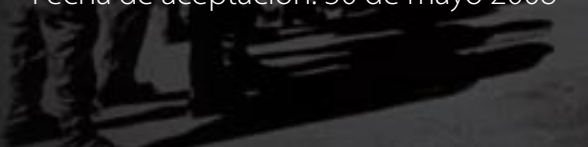

De la economía autocentrada a la plena participación en los mercados. El cambio agrícola en el distrito de El General, Pérez Zeledón: 1950 y 1980.

Miembros del Consejo Editorial:

Dr. Ronny Viales, Dr. Juan José Marín

Editores Técnicos:

Allan Fonseca, Andrés Cruz, Gabriela Soto
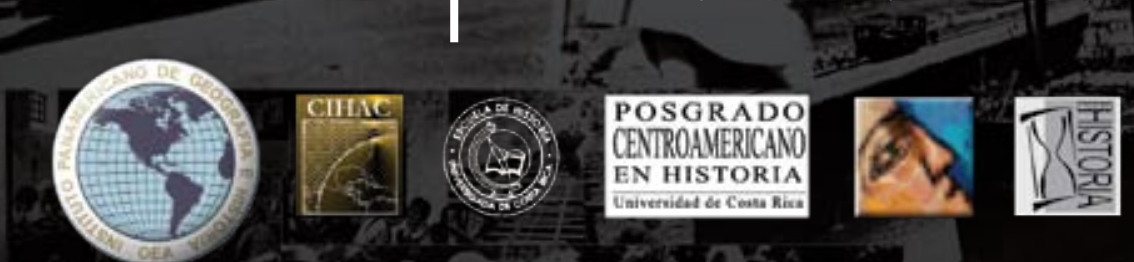
Indexaciones: Repositorio de Revistas UCR, DIALNET, Latindex, REDALYC Directorio y recolector de recursos digitales del Ministerio de Cultura de España, Directory of Open Access Journals. Diálogos Revista Electrónica de Historia ISSN 1409-469X. Número especial 2008. Dirección web: http://historia.fcs.ucr.ac.cr/dialogos.htm

\title{
De la economía autocentrada a la plena participación en los mercados. El cambio agrícola en el distrito de El General, Pérez Zeledón: 1950 y 1980.
}

\author{
M.Sc.Norman Dimas Durán Barrantes
}

\begin{abstract}
Master en Historia Aplicada con Mención en Estudios Agrarios y profesional en la enseñanza de Estudios Sociales por la Universidad Nacional, Heredia, Costa Rica. Actualmente se desempeña como profesor de Historia Universal en United World College Costa Rica. E-mail: normanduranbarrantes@costarricense.cr
\end{abstract}




\section{Resumen:}

Esta ponencia aborda el proceso de desarrollo de las unidades productivas ubicadas en el distrito de El General, Pérez Zeledón, entre 1950 y la década de 1980. Se analizan aquí, desde la perspectiva de la historia regional, las rutas que emplearon los productores de frontera agrícola para vincularse al mercado nacional; así como la incidencia que los procesos de cambio técnico y organizacional, tuvieron en el cimiento de una economía completamente capitalizada e integrada al entorno económico costarricense.

Palabras clave: El General, historia agraria, transformaciones en la agricultura, agricultura, economía.

\section{Introducción}

Parece certero afirmar, como desde hace ya algún tiempo lo hicieran algunos especialistas dedicados al estudio de los procesos agrarios, que todavía en el período anterior a 1950 existían en Costa Rica amplias áreas de reciente colonización y considerables superficies no integradas a un mercado nacional unitario. Que esto era producto, entre otras cosas, de los deficientes sistemas de comunicación y de las dificultades para el traslado de los productos hacia los principales centros urbanos; variables que habían obligado a miles de agricultores a mantenerse dentro de un modelo de autosubsistencia con una escasa articulación al mercado. También sería efectivo sostener que a partir de mediados del siglo XX esta situación cambió radicalmente, cuando el fuerte impulso en la construcción de vías y el desarrollo de medios de comunicación impulsado por los gobiernos socialdemócratas de la época, permitió integrar dichos espacios al mercado nacional, ocasionando que las relaciones de producción de corte capitalista dominantes en la Depresión Tectónica Central pudieran extenderse a la mayor parte del territorio, completándose de esta forma la unidad económica del país. De tal manera, la producción destinada al autoconsumo, que todavía hacia 1960 conservaba cierta importancia, habría declinado casi por completo durante la década de 1970, con lo que la agricultura experimentó un profundo proceso de mercantilización. ${ }^{1}$

Es indudable que afirmaciones de este tipo resultan certeras para algunas zonas situadas al sur del país pues, en claro contraste con la Depresión Central y otras regiones de del país, el 
decenio de 1950 fue el primer período en la historia de sectores como el Valle de El General en que se generaron fuertes lazos con el mercado; esto, como parte de un proceso que tuvo lugar tras casi un siglo de relativo aislamiento, debido en lo fundamental a la falta de contactos con los principales centros poblacionales del entorno nacional. ${ }^{2}$ A partir de la construcción del tramo de la Carretera Interamericana Sur hasta el poblado de San Isidro, el cual fue concluido en el año de 1946, Pérez Zeledón se integró definitivamente al entorno costarricense. La radical mejora en las posibilidades de acceso a la zona dio pie a un notable aumento demográfico, a la activación del mercado local y al desarrollo de vínculos más estables y variados con el mercado. Junto a ello, una mayor presencia del aparato estatal contribuyó ampliamente al desarrollo productivo y de los intercambios de corte capitalista. Producto de lo anterior, el conjunto de unidades productivas que habían eclosionado al amparo de la frontera agrícola, ya para 1950 tenían un carácter bien definido dentro de una economía familiar campesina en pleno crecimiento e iniciaban su participación en un proceso que condujo hacia una dinámica de mayor diferenciación agrícola, económica y social de los productores.

A la vista de lo hasta ahora expuesto, esta ponencia indaga las unidades y de los sistemas productivos en el Valle de El General, a partir de un estudio de caso que toma como escenario el distrito de El General, Pérez Zeledón, en el marco de su vinculación formal con el mercado nacional. Dentro de un contexto en que los fundos integrados a una economía autocentrada pasaban a convertirse en unidades cuya característica fundamental era la búsqueda de conexiones con nuevos circuitos de intercambio; se aporta un análisis general del proceso de transición hacia un modelo en el que las señales del mercado que emanaban desde la Depresión Tectónica Central empezaron a redefinir los perfiles del horizonte agrario hasta entonces conocido, tanto como los intereses y las estrategias empleadas por los productores que habitaban en la zona. 


\section{O $99^{\circ}$ CONGRESO

Indexaciones: Repositorio de Revistas UCR, DIALNET, Latindex, REDALYC Directorio y recolector de recursos digitales del Ministerio de Cultura de España, Directory of Open Access Journals. Diálogos Revista Electrónica de Historia ISSN 1409-469X. Número especial 2008. Dirección web: http://historia.fcs.ucr.ac.cr/dialogos.htm

\section{Mapa No. 1}

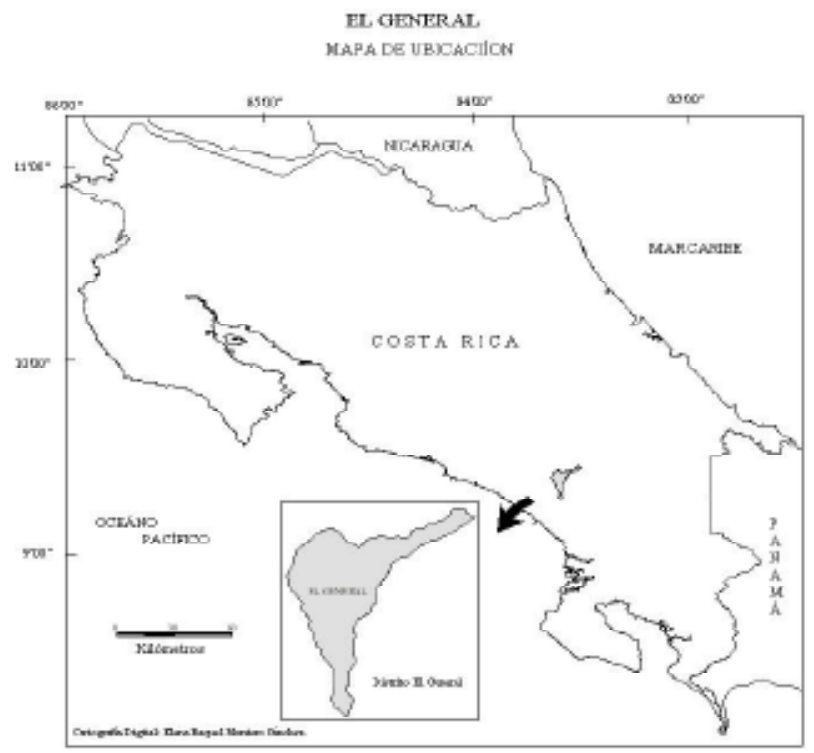

Distrito de El General, Pérez Zeledón, San José, Costa Rica 
Para lograr una visión dinámica del proceso, el ejercicio investigativo parte de una imagen inicial que caracteriza la lógica de funcionamiento de las fincas existentes en la región hacia mediados de siglo. El empleo del Censo Agropecuario de 1955 permitió en este caso un acercamiento por medio de un análisis cuantitativo y cualitativo a la dinámica microeconómica de cada una de las tenencias agrarias. La metodología propia del enfoque sistémico para el análisis de las unidades y los sistemas de producción hizo posible captar los razonamientos sobre los que se regían los distintos tipos de productores, establecer una tipificación a partir de sus características particulares y medir su eficiencia técnica y económica.

Con el objeto de percibir el cambio productivo, técnico y organizacional que se operó durante el período; fue pertinente considerar la dimensión exacta del impacto estatal e institucional en la difusión o implantación del conjunto de transformaciones que afectaron a los sistemas de producción. Pese a que no resultó para nada sencillo establecer los límites cronológicos de una combinación tan compleja de innovaciones organizativas, técnicas y económicas, a la que generalmente se conoce bajo el apelativo de modernización del agro. Esta investigación se acerca a ello fundamentándose en fuentes secundarias y en una selección de informantes extraída de las bases de datos disponibles, a partir de la cual los mismos productores ayudaron a reconstruir la evolución histórica distrital. Una vez definido este escenario, se estudió el tránsito de las unidades y los sistemas de producción a lo largo del período en que fue dominante el Estado Interventor en Costa Rica. Para lo anterior, se rastrearon los cambios que se habían tenido que implantar a lo interno de las fincas con el objeto de mantener vigencia participativa dentro del espacio agrario, siguiendo muy de cerca el comportamiento mostrado por los agentes sociales actuantes ante las transformaciones que se estaban impulsando desde la esfera estatal. Esto implicó una recuperación histórica basada en censos, fuentes documentales primarias y de carácter oral, con 
el fin de recrear las vías evolutivas de los distintos sistemas. ${ }^{3}$ Entendiendo la naturaleza del proceso transformador se pudo establecer, de manera bastante fiable, cuál había sido el impacto general de las modificaciones acaecidas.

\section{Características agrícolas del distrito de El General en 1955}

En el Censo Agropecuario de 1955 se registraron en el distrito de El General un total de 172 unidades productivas; es decir, el 7.5 por ciento del total de las 2666 fincas que existían en el cantón de Pérez Zeledón. La distribución de la tierra entre los agricultores seguía muy de cerca el patrón de colonización que había experimentado la zona, de modo tal que los sectores con mayor concentración de unidades productivas fueron los originalmente ocupados por los inmigrantes mestizos a lo largo de la segunda mitad del siglo XIX; mientras que en las zonas en que existían mayores limitaciones agroecológicas no se reportaba la presencia de unidades productivas de ningún tipo. ${ }^{4}$

En lo referente a la situación jurídica de la posesión del suelo, El General se caracterizaba por un tipo de tenencia en que era ampliamente mayoritaria la propiedad privada explotada directamente por el productor; seguida, pero muy de lejos, por otros tipos de tenencia, terrenos explotado de forma gratuita, en alquiler, tomadas sin permiso y tierras en esquilmo. Refiriéndonos a la combinación de tipos de tenencia podemos notar un mayoritario número de unidades donde únicamente existía la explotación directa, seguida por las fincas en cuyos terrenos, junto a este uso, aparecían pequeños sectores de las restantes formas de tenencia, especialmente gratuita y en alquiler. Aquellas unidades exclusivamente conformadas ya sea por tenencia gratuita, otros tipos de tenencia, alquiler, esquilmo o cualquier combinación entre ellas, no llegaron a ser significativas, ni en términos numéricos ni de extensión, considerándose más bien como 
excepciones o casos aislados dentro del conjunto.

Durante la etapa el distrito también se caracterizó por un consistente dominio de las propiedades medianas y pequeñas, presentando un índice de concentración de la tierra que sin ser extremo tendía a ser alto. Lo anterior se debió a la presencia en la región de algunas fincas grandes y muy grandes que lograron captar un importante porcentaje de superficie. De esta manera, el conjunto de unidades menores a las 10.0 Has, que representaban el 50 por ciento de los casos, cubrían solamente el 9.0 por ciento del área. Las fincas medianas, entre 10.0 y 50.0 Has, constituían el 41 por ciento de las unidades y abarcaban el 43 por ciento de la extensión total. Aquellas entre 50.0 y 100.0 Has, que podríamos considerar como fincas grandes, eran el 7 por ciento de las tenencias y ocupaban una extensión del 28 por ciento del espacio. Finalmente, existía un número limitado de fincas muy grandes (2\%), con extensiones superiores a las 100.0 Has, cubriendo una superficie equivalente al 20 por ciento del área total.

Se estableció, en consecuencia, un tipo de apropiación que partiendo del fondo de valle y las terrazas del Río General y Peñas Blancas, avanzó en forma paulatina sobre la gradiente de la Cordillera de Talamanca. En este proceso se trataron de aprovechar, en primer término, los terrenos agroecológicamente más aptos para el desarrollo de una economía de producción diversificada y, sólo posteriormente, se pensó en la ocupación de aquellas zonas con limitantes físicas, geológicas, climáticas o de comunicación.

\section{Uso del suelo en el distrito de El General}

Es imposible poner en duda el hecho de que las condiciones de la región habían cambiado mucho desde la llegada de los primeros colonos a estos parajes. Para 1955, en El General ya existían un total de 3950.7 hectáreas en uso y el 45 por ciento de los sectores ocupados ya 
habían sido mejorados por medio del desmonte. Del área empleada, la mayor parte eran bosques, le seguían los charrales, inmediatamente después hacían su aparición los repastos, así como los potreros. Una superficie comparativamente menor se dedicaba a los cultivos anuales y a los cultivos permanentes, para finalizar con los sectores destinados a otros tipos de tierras de cultivo. Pese a que los espacios boscosos seguían siendo dominantes, su extendida explotación y la existencia de importantes áreas en charrales y tacotales, eran claro indicio de la existencia de procesos de tala y desmonte en plena ejecución. Es posible afirmar, por lo tanto, que para mediados del siglo XX el distrito de El General era todavía una región en franca actividad de establecimiento y desarrollo de unidades productivas. Sin embargo, en cada una de las zonas agroecológicas los ritmos seguidos por esta dinámica habían sido distintos y en algunos sectores la mayor parte del área permanecía sin explotar, tal era el caso de la región montañosa de la Cordillera de Talamanca. ${ }^{5}$ Esto nos permite deslindar algunos aspectos puntuales, por ejemplo, que las superficies en donde se inició un proceso de apropiación más temprana fueron lo más profusamente explotadas; por su parte, aquellos en los que se hacían evidentes algunas las desventajas comparativas en términos agroecológicos o de comunicación permanecieron casi intactos. En este constante reto de supervivencia frente al medio, los agricultores implementaron distintas estrategias productivas, con lo que las diferencias entre unos y otros se tradujeron finalmente en sistemas de producción con características particulares.

\section{Perfil productivo del distrito de El General en 1955}

Para 1955 en el distrito de El General un 84.3 por ciento de las fincas poseían cultivos anuales de diferentes tipos. En las unidades productivas existentes se sembraron 23.5 Has de arroz (Oryza sativa) que produjeron alrededor de 256 quintales por año. En lo referente a la producción 
de frijoles (Phaseolus vulgaris L.), la adaptabilidad de la leguminosa permitió que su cultivo se diera a lo largo y ancho del distrito en un total de 83.3 hectáreas, que producían alrededor de 1 879 quintales anuales. En vista de la cualidad que posee la planta de fijar nitrógeno en el terreno, es muy posible que además se haya empleado como un tipo de regenerador natural en aquellos sectores de alto desgaste o en asocio con cultivos que presentaban elevados requerimientos de este elemento. El maíz (Zea maíz L.) fue, con 177.2 hectáreas, el tipo de grano que tuvo mayor difusión en todas las zonas explotadas del distrito, pues en las milpas se recogieron hasta 493 fanegas del producto. Al igual que los otros tipos de granos, el maíz vino a constituirse en un producto muy vinculado a la economía de autoconsumo, pero solo parcialmente empleado para el intercambio comercial.

Para la fecha sólo el 2.3 por ciento de las unidades del distrito poseían plantaciones de tabaco (Nicotiana tabacum), exclusivamente distribuidas en las veras del Río General. Los datos analizados permiten ver al tabaco como un producto que presentó una llamativa contracción en su crecimiento, en especial, al comparar su desarrollo con etapas anteriores, cuando su comercio fue vital para los colonos que se asentaron en el valle. ${ }^{6}$ La construcción de la Carretera Interamericana, que favoreció el crecimiento y proliferación de otros tipos de prácticas agrícolas; pero que también facilitó el control sobre ciertas actividades económicas en las que el Estado históricamente tuvo un interés muy particular, pudo haber sido un elemento clave en este proceso; pues habría contribuido a desacelerar la producción que a nivel local se habían practicado, relevando a la planta de su papel como uno de los únicos productos susceptibles de intercambio comercial.

El área destinada al cultivo de yuca (Manihot sculenta) fue de 12.7 hectáreas. Del total de la producción se logró colocar en el mercado el 13 por ciento, con lo que la mayor cantidad 
del tubérculo se destinó para el consumo interno, lo que deja de relieve su jerarquía como componente vital dentro del abastecimiento de las unidades del distrito. Un papel semejante habrían jugado cultivos homólogos como la papa “chiricana”, el ñampí, el ñame, el tiquisque, el camote o la malanga, que aunque no considerados en los registros censales, posiblemente por la poca sistematización de los sembradío, fueron recursos de común aprovechamiento en la cocina de los productores. El 72 por ciento de las fincas del El General poseían plantaciones de plátano, guineo o banano, con lo que podemos apreciar que el cultivo de especies musáceas (Musaceae) en el distrito fue considerable. Dada la excesiva oferta del producto su venta no fue muy amplia; de este modo, podríamos asegurar que el cultivo cumplió tres tipos de funciones bien definidas: en primer término como producto alimenticio dentro de las fincas; como sombra en los cafetales y, finalmente, si el nivel de demanda o las oportunidades comerciales así lo permitían, en forma de producto destinado al mercado.

Como era natural de una región en la que prevaleció una agricultura de corte tropical, el 62 por ciento de las fincas eran productoras de frutas. Sin embargo, la superficie que se destinó a su desarrollo como cultivo único fue bastante limitada. Por tanto, rigió un tipo de escenario agrícola semejante al de las musáceas, en el que las plantas de distintas variedades se encontraban diseminadas al interior de las propiedades, producto de una siembra más o menos sistemática destinada en algunos casos a brindar sombra sobre cultivos permanentes o como simple resultado de la generación espontánea. En las unidades del distrito se registró la existencia de aguacate, árboles de naranja, piña, otros cítricos de la familia de las Rutáceas, cocoteros y pejibaye. De las frutas producidas se ubicaron en el mercado cantidades variables que iban desde el 7.5 por ciento de las piñas, hasta un 91.2 por ciento de los pejibayes, mientras otras muchas variedades posiblemente eran aprovechadas únicamente para un tipo de autoconsumo estacional. 
Aunque en esta región todavía era predominante el cultivo cafetalero bajo formas tradicionales, era posible notar para la fecha un franco crecimiento de las áreas sembradas y un gran dinamismo en la constitución de nuevas plantaciones. El cultivo varió en acuerdo con las necesidades agroecológicas específicas de cada zona y al nivel de tolerancia que los productores mostraron hacia la adopción de nuevas variedades. Así, durante los primeros años de la década de 1950, al ampliarse las posibilidades en el mercado de café la estrategia de estos productores -sin llegar a la negación del cambio- parecía estar ligada a evitar cualquier tipo de riesgo manteniendo formas tradicionales de siembra en los sectores de más antigua ocupación, donde las plantaciones ya habían demostrado ser rentable. Esta lógica indicaba un particular interés en que los sembradíos captaran los menores esfuerzos en términos de aprendizaje; pero, sobre todo, que no asimilara grandes cantidades de capital. Por su parte, en los sectores agrícolas de más reciente fundación los paquetes tecnológicos propuestos por la Revolución Verde empezaron a tener más impacto, especialmente en unidades dispuestas a realizar el tipo de inversión necesaria para acceder a la modernización de los cafetales. Es posible afirmar que el acceso al mejoramiento técnico en el manejo de las plantaciones cafetaleras del distrito fue dominado en principio por la introducción de nuevas variedades y técnicas de siembra, elementos que habrían influido positivamente en lo tocante a la mejora de los rendimientos y la resistencia de las plantaciones al embate de plagas y enfermedades; antes que por la adopción de otros tipos de implementaciones técnicas, que por su costo estuvieron restringidas a las unidades con mayores posibilidades de inversión en equipo e insumos. De esta forma, el café se estableció como el cultivo de mayor dinamismo que presentaba el distrito y en el que se invirtió la mayor cantidad de recursos con el fin de lograr, no sólo la ampliación de las áreas, sino la mejora y modernización de las plantaciones.

Un total de 90 fincas (52.3\%) aparecían como productoras de caña de azúcar. En ellas la 
mayor área fue ocupada por la caña entresacada (95.2\% del área total), en las que se generaba el 94.3 por ciento de la producción; mientras que la caña de ajecho estaba presente en sólo el 4.7 por ciento de las plantaciones, produciendo únicamente el 5.6 por ciento del tonelaje. De tal manera, el cultivo de esta planta perenne seguía realizándose a partir de la utilización de variedades y técnicas tradicionales, con una exigua renovación o ampliación de los cañaverales. Todas las anteriores pruebas nos remiten a un tipo de actividad de autoabastecimiento que formó parte de unidades diversificadas con faenas distribuidas en el calendario de trabajo a lo largo del año, entre otras cosas, ahorrativas de mano de obra e inversión de capital.

En el distrito el 71.5 por ciento de las unidades productivas poseían ganado porcino o caballar; sin embargo, la existencia de pequeños hatos dedicados por completo a la cría para el consumo interno no hacía constar que la cría de cerdos tuviera un auge en la proporción antes habitual. De manera inequívoca había pasado el tiempo en que la venta de "chanchos" era un elemento de vital importancia dentro de la economía de los generaleños y tal como lo confirman los censos, es evidente que a partir de este momento dicho tipo de proceso productivo fue languideciendo.? El hato equino tenía mayor peso, sobre todo si analizamos el papel que desempeñaba la tracción animal en un contexto en que la mayor parte de los caminos de la región eran todavía de piedra y donde predominaban los trillos o veredas, sólo posibles de transitar a pie o a lomos de una bestia, especialmente en la época lluviosa.

Por su parte, la ganadería vacuna fue una actividad que se encontraba en pleno crecimiento. Desarrollada extensivamente, se vinculó a la producción de leche, carne y, por último, al trabajo. ${ }^{8}$ Al interior del hato existía un claro predominio de las vacas adultas por sobre otros especimenes y el número de animales de raza criolla superaba en mucho a la ínfima cantidad de ganado puro. Lo anterior muestra algunas líneas básicas que definían claramente el tipo de actividad 
que estaba desarrollándose en la zona; primero, que las unidades mantenían en su poder a las hembras, tanto para fines de reproducción como para el aprovechamiento de los lácteos y, en segundo término, que la poca capacidad económica de la mayoría de los productores llevó a que la mejora del hato tuviera lugar por medio del paulatino cruce de ganado, antes que por la inversión directa en la compra de animales de casta. Fruto del tipo de ganadería que se estaba desarrollando, la producción de lácteos tuvo lugar en el 60 por ciento de las unidades; de hecho, el elevado consumo de leche y derivados nos indican que este tipo de actividad fue uno de los componentes de mayor importancia dentro de la economía desarrollada al interior de dichos sistemas agrícolas. ${ }^{9}$

Laganaderíadecarneproponíaporsuparteuna dinámica más ligada conla comercialización, especialmente de aquellos especimenes en etapa de crecimiento. En este caso, la existencia de animales de raza y enrazados fue mayor, lo cual era muestra de un esfuerzo consciente por mejorar el hato. De esta manera la estrategia económica de las unidades contemplaba la cría de ganado de carne hasta ciertas etapas de crecimiento, punto en que era tratado en coyunturas favorables. De acuerdo a la perspectiva que hemos podido concretar, aun cuando en términos generales la actividad lechera estaba más desarrollada, empezaba a evidenciarse un mayor interés de los productores por el desarrollo de la ganadería de carne. Era manifiesto que se asistía a un viraje en el énfasis productivo de la actividad, en acuerdo a las nuevas condiciones comerciales. ${ }^{10}$

Tras la descripción del escenario que regía la producción en El General, el lector habrá podido darse cuenta de un elemento sustancial, el cual refiere a la autonomía alimentaria alcanzada en la región, misma que venía aun desde antes del despegue comercial producido por el establecimiento de las vías de comunicación. En adelante, este factor habría de convertirse en un elemento clave para la exitosa inserción de la zona en el mercado nacional, pues la 
autosostenibilidad lograda dio margen a los productores para realizar un tránsito in crescendo hacia una etapa de relaciones comerciales más profundas.

\section{Asociación de actividades y sistemas de producción agrícola}

La agricultura existente al interior del distrito adquirió un carácter particular en atención a factores como la desigual distribución de la tierra y el uso del suelo. Pero, adicionalmente, sus características variaban como consecuencia de los tipos y formas que adquiría la producción, por lo que el modo de ordenamiento de las distintas combinaciones de actividades agrícolas se agregaron como elementos que establecían un factor de diferenciación, no sólo a nivel de las distintos espacios físicos que conformaban el distrito, sino entre los mismos productores que habitaban cada una de las zonas productivas.

Producto de las posibilidades agrícolas existentes en el valle, en 1955 existían hasta 32 tipos de combinaciones productivas. Estas iban desde unidades que presentaban una sola actividad económica, hasta fincas que combinaban siete productos distintos; siendo el café el cultivo que aparecía con mayor frecuencia, seguido por los granos, la explotación ganadera, la caña de azúcar, el bosque y la producción tabacalera. En este universo agrícola cerca del 55 por ciento de las fincas combinaron uno o más cultivos anuales o permanentes con el desarrollo de actividades pecuarias. Menor constancia mostraron las unidades que vinculaban cultivos anuales con cultivos permanentes, aquellas productivamente especializadas en la obtención de granos o café y las fincas que se dedicaron al monocultivo asociado a ganadería.

Presente en todas las zonas, la suma de granos/café/caña/ganado leche/ganado carne/ bosque fue a la que con mayor frecuencia acudieron los agricultores, concretándose como la matriz productiva del distrito. Desarrollada a partir de una estrategia de diversificación en la 
que se integraban cultivos estacionales, anuales y perennes, ganadería y la explotación forestal; junto a productos "secundarios" como frutas, tubérculos, musáceas, aves de corral, ganado porcino, caballar y otros, esta composición fue medular al construir una economía de carácter mixto, donde junto a las tareas destinada al aprovisionamiento de las unidades, paulatinamente encontraban cabida aquellas actividades cuyo producto se dirigía al mercado. Lo anterior nos indica que los productores de la zona seguían basando su práctica en la diversidad, siendo el eje de la lógica productiva una estrategia marcada por la suma de actividades como vía para obtener la máxima racionalidad económica en unidades productivas que apenas empezaban a disfrutar de ciertos contactos estables con el mercado. Por otra parte, aunque las fincas especializadas mostraban importancia numérica, siempre correspondían a dominios de pequeña extensión, por lo que su área total era de poca envergadura. Asimismo, las unidades que desarrollaban prácticas productivas fundamentadas en la combinación de cultivos anuales con cultivos permanentes, pese a que ocupaban áreas de cierta relevancia, no fueron numéricamente trascendentes.

La diversidad agrícola del distrito originó la existencia de diferentes tipos de sistemas de producción. ${ }^{11}$ Un conjunto cercano al 50 por ciento de las unidades del distrito, extendidas en un 9 por ciento del área en estudio, eran minifundios que no superaban las 10 hectáreas. Con una superficie promedio que oscilaba entre 0.5 y 6.5 Has, en estas fincas era dominante el trabajo familiar, haciéndose un uso muy ocasional de la mano de obra contratada. Más comunes en el fondo de valle y las terrazas del Río General, eran bastante parecidas en itinerarios técnicos; distinguiéndose, sin embargo, en lo tocante a producción y rendimiento, de ahí que se pudiera establecer la existencia de varios subtipos. En primera instancia, aparecía un conjunto de unidades especializadas en la producción de granos. Se trataba de sistemas cuyas principales limitantes radicaban en su poca capacidad económica y en lo restringido del área que tenían a disposición, 
por lo que en las etapas de inactividad los productores se enfrentaban con la necesidad de ampliar sus ingresos incorporando a sus calendarios ciclos de labor fuera de la finca; ya como peones, jornaleros, o bien, en otros tipos de actividad.

Las unidades minifundistas especializadas en la producción de cultivos permanentes poseían cafetales con extensiones promedio de 0.7 Ha y la mayoría eran manejadas por los mismos propietarios; aunque en los meses de final y principio de año algunas de ellas pudieron requerir de algún tipo de labor extrafamiliar. Ocuparon en el trabajo de la finca únicamente una parte de su calendario laboral, por lo que no resultaba extraño que cuando declinaban las faenas recurriesen a la venta de mano de obra como una posibilidad de obtener ingresos extra.

La integración de producciones anuales y cultivos permanentes en un mismo terreno generó la existencia de minifundios basados en el policultivo. Con áreas promedio de 4.8 Has, eran unidades que cultivaban granos, pequeñas áreas de café y caña de azúcar como productos asociados. Comparados con los minifundios anteriormente analizados, dichos sistemas integraban de una mejor manera sus calendarios laborales. Sin embargo, en la mayor parte de los casos no llegaron a ser por sí mismos sistemas económicamente viables y sus propietarios tuvieron que recurrir a la venta de su fuerza de trabajo para superar los umbrales de subsistencia. Nuevamente fue la carencia de espacio la limitante más sobresaliente.

El grupo más exitoso fue el que asoció cultivos anuales y permanentes con ganadería. La cría de ganado a baja escala fue ventajosa pues no requirió de una gran inversión de trabajo, lo cual permitió integrarla dentro del sistema sin llegar a comprometer los calendarios de otros tipos de actividades. Este conjunto de productores se caracterizaba por poseer terrenos donde dominaban el cultivo cafetalero, de granos, la presencia de pequeños repastos para el mantenimiento del ganado y la caña de azúcar. También aquí la lógica productiva giraba en torno 
a la utilización intensiva de la mano de obra familiar y de la tierra, para una producción destinada en su mayor parte al autoconsumo. Pese a ello, el énfasis que estas unidades trataban de asignar a la producción para el mercado, las convirtió en fincas con mayor complejidad y un desempeño económico global más eficiente. Considerando que los ingresos obtenidos por estos productores procedían estrictamente del valor agregado que podían obtener de sus fincas y de la eventual venta de mano de obra, el reto básico al que se enfrentaron los minifundistas del distrito era la óptima organización de sus calendarios de trabajo, en acuerdo a las limitantes de superficie que enfrentaban.

Las fincas con extensiones por encima de las 10 Has; pero inferiores a las 50 Has, representaban el 41 por ciento de los casos y abarcaban el 43 por ciento del área del distrito. Con una superficie promedio entre 10 Has y 35 Has, eran propiedades que habían explotado en promedio el 70 por ciento de su área, por lo que la mayor parte de ellas aún presentaban superficies en reserva. En este tipo de unidades, pese a que existía una limitada integración de capital, se practicaba una agricultura diversificada que actuó bajo una racionalidad en que se trataba de maximizar, mediante la conjunción de variadas actividades en un mismo calendario productivo, el aprovechamiento del trabajo familiar y el empleo extensivo de la tierra.

Dentro de los medianos productores se podían diferenciar varios grupos, el primero de ellos estaba compuesto por unidades especializadas en la producción de cultivos permanentes. En este conjunto fue importante la presencia de fincas especializadas en la producción de café y unidades que, por estar en proceso de constitución, combinaban esta actividad con la "voltea" de montaña. Dada la etapa de desarrollo en la que se encontraban estas explotaciones, no habían logrado obtener total viabilidad económica y como consecuencia, sus propietarios tuvieron que desarrollar estrategias en donde junto a las faenas efectuadas en la unidad acudieron a la venta 
de su fuerza de trabajo como una vía para obtener ingresos monetarios adicionales.

En segundo lugar existía un importante grupo de fincas que asociaban el policultivo, la ganadería y la explotación forestal. En vista de que algunas estaban en pleno proceso de tumba de bosque, a la labor agrícola debía agregarse el trabajo invertido en la deforestación, actividad que completaba los calendarios laborales. De tal modo, aun cuando eran unidades que no estaban constituidas en su totalidad y en ocasiones tenían que invertir en mano de obra, factor que reducía sus ingresos netos, se convirtieron en fincas económicamente rentables pues la totalidad de ellas complementaba sus entradas con la explotación de los recursos forestales .

Un tercer grupo estaba constituido por las medianas unidades con asociación de policultivo y ganadería. Se trataba de productores que administraban unidades ya constituidas (explotadas en al menos un 90\%), donde predominaban los potreros, los cultivos permanentes, los cultivos anuales y los charrales. Pese a contar con una escasa cantidad de equipo agrícola, se trató de fincas bastante diversificadas donde se integraba una producción compleja. Así, aun cuando presentaron itinerarios muy parecidos a las unidades en constitución, los mayores promedios de área de cultivo, una mejor productividad y el hecho de estar exentas de las labores de tumba de bosque, las convirtió en fincas con una mayor viabilidad económica.

Por sus características la mayoría de estos sistemas eran intensivos en trabajo y debían recurrir a la contratación de mano de obra para superar los "picos" laborales que se daban principalmente a final de año cuando coincidían la cosecha de café, la limpieza de potreros y la recolección de granos del segundo ciclo de cultivo, prueba clara de crecimiento que estaban experimentando. De esta manera, la dinámica de estas unidades fluyó primero por la vía de intensificar el empleo de la mano de obra disponible dentro de fincas con la explotación extensiva de la superficie y, en segundo término, integrando mano de obra externa para lograr el objetivo 
de fortalecer los vínculos al mercado por medio de productos como el café, los granos o el ganado.

Aquellas unidades con espacios entre las 50 y 187 hectáreas, que podríamos considerar como fincas grandes, eran el 9 por ciento de los casos y ocupaban una extensión del 48 por ciento del área del distrito. Dentro de este conjunto se distinguían los productores que recién iniciaba la explotación de las fincas y cuyo trabajo se encontraba concentrado en la tumba de bosque y la explotación de recursos forestales. En un segundo grupo se localizaron unidades en constitución que asociaban el policultivo, la ganadería y la explotación forestal. Estas fincas funcionaron bajo una racionalidad que radicaba en la explotación intensiva de factores de producción como la mano de obra familiar, el uso extensivo de la tierra y la explotación directa de los recursos del medio. Su inversión en equipo agrícola era mínima y las principales actividades que desarrollaban eran la producción de granos, café, ganadería de doble propósito y caña de azúcar; además de contar en todos los casos con reservas de bosque. Dadas sus características, desarrollaron una modalidad económica donde la baja capacidad de inversión de capital trataba de ser subsanada con la paulatina ampliación del área productiva.

Un tercer conjunto estaba conformado por las unidades que se podían incorporar dentro de la categoría de fincas ya constituidas. Este tipo se orientó a la producción diversificada de bienes agropecuarios, algunos de los cuales permitieron una vinculación de relativo éxito con el mercado. Se trataba de las fincas técnicamente más desarrolladas del distrito, con equipo agrícola compuesto básicamente de carretas, arados, trapiches; que en la mayor parte de los casos contaban con crédito. Por tratarse de explotaciones de gran tamaño, pero que no llegaban a ocupar el status de unidades empresariales, en ellas el trabajo familiar se combinaba frecuentemente con la contratación de mano de obra. Sin embargo, pese a la evidente dinámica mostrada por 
estas unidades, ni la superficie disponible, ni la creciente integración de capital y mano de obra en las actividades agropecuarias; lograron constituirse en elementos que les proporcionaran ventajas económicas apreciables con respecto a otros tipos de sistemas productivos y, en consecuencia, fueron fincas que apenas superaban los umbrales económicos mínimos requeridos para la subsistencia. Esta aparente contradicción se explica en los elevados costos que requería el mantenimiento y desarrollo de este tipo de sistemas, sobre todo, en etapas en que muy probablemente las fincas estaban en plena construcción.

Tan variadas como fueron las formas en que las distintas actividades se integraban dentro de los sistemas productivos, también lo fue la rentabilidad obtenida por cada uno de los grupos de productores. En este sentido, hemos logrado calcular que para la fecha, el valor agregado anual promedio de los minifundios era de aproximadamente $\$ 1240$ colones, con lo que solamente el 27 por ciento de las fincas lograban superar el umbral para la reproducción de sus sistemas productivos. De hecho, existían grandes contrastes en el ingreso obtenido por cada una de las unidades, el cual se distribuía de manera desigual según el tipo de sistema productivo que se implementara. ${ }^{12}$ En este conjunto los más rentables fueron los minifundios dedicados a la producción exclusiva de cultivos permanentes, aquellos con asociación de policultivo-ganadería y los que combinaron la producción de granos y ganado, que en términos generales lograban la reproducción de sus sistemas o se acercaban bastante a este objetivo. Las fincas con ingresos más bajos se ubicaban entre las unidades especializadas en la producción de granos y las dedicadas al policultivo; ninguna de las cuales lograba reproducirse por si mismas y para subsistir como productores agropecuarios, se vieron en la imperiosa necesidad de complementar los ingresos obtenidos con la venta de su fuerza de trabajo. Por lo tanto, si algo es notable en el desempeño económico de este tipo de fincas, es el hecho de que aun cuando la escasa disponibilidad de tierra 
era indiscutiblemente un factor limitante en su desarrollo económico, igualmente decisiva fue la escogencia de las actividades realizada por los productores para la estructuración de los sistemas que administraban.

Las fincas en propiedad de medianos productores fueron las que obtuvieron, con un promedio de $\$ 2984$ colones, el valor agregado anual más alto de todos los sistemas productivos del distrito, muestra de lo cual era el hecho de que el 79 por ciento de estas unidades productivas eran económicamente viables; esto, además de proporcionarles una clara capacidad de acumulación de capital, favorecía ampliamente las opciones de ampliar los montos de reinversión dentro de sus posesiones. Los sistemas con mejores ingresos fueron las medianas unidades ya constituidas que combinaban policultivo-ganadería, seguidas muy de cerca por las unidades en proceso de constitución que asociaban el policultivo y la ganadería con la explotación forestal. Las fincas con especialización en cultivos permanentes, con o sin explotación forestal, eran los que mostraban la más baja rentabilidad y en consecuencia se mantuvieron por debajo de los umbrales de reproducción. En este sentido los productores de sistemas especializados, al igual que sucedió en los minifundios, es muy posible que también hubiesen tenido que recurrir a la venta de su fuerza de trabajo para obtener un complemento a sus ingresos.

Finalmente, pese a contar con mayor área y más posibilidades de ampliar sus explotaciones, las grandes fincas, aun cuando en su totalidad lograban la reproducción de sus respectivos sistemas, no eran las unidades que obtenían el mayor valor agregado anual del distrito. Sin embargo, era evidente que se trataba de los productores con mayores recursos económicos disponibles y los que a mediano plazo reunían las mejores expectativas de desarrollo; pues además de poseer fincas y hatos ganaderos de mayor tamaño, eran el grupo que invertía más en la mejora y ampliación de sus sistemas. 
En este escenario, donde la comercialización de productos agropecuarios a gran escala apenas daba sus primeros pasos, la diversificación productiva y la producción para el autoconsumo seguían siendo elementos básicos de la actividad agrícola. Así, de acuerdo al análisis realizado, aunque existían claras desigualdades en el desarrollo de los sistemas de producción ubicados en las distintas zonas del distrito como consecuencia, sobre todo, de diferencias agroecológicas palpables que se reflejaban de una manera u otra en la rentabilidad de las unidades productivas; al menos para esta etapa, la relación entre factores de producción y el ingreso de las unidades productivas no resultaba ser tan directa y clara como se podría suponer. De acuerdo a lo visto, es posible que el éxito de las unidades tuviera tanta relación con las decisiones que el productor adoptaba, en términos de la organización de las estrategias productivas al interior de la unidad, como con los recursos o ventajas comparativas con que disponía la finca. Es decir, en última instancia, el mayor o menor éxito alcanzado por los sistemas de producción estuvo tan vinculado a la disponibilidad de recursos productivos, como a la adecuada lectura que hiciera el productor del ámbito en que se desarrollaba y, de manera concomitante, a las estrategias productivas que en consecuencia fueron adoptadas.

A este punto, aunque es evidente que el proceso no había conquistado todas las perfecciones articulares de un modelo ideal, la gestión de los agricultores generaleños podía catalogarse de exitosa pues, al menos hasta haberse cumplido la primera mitad del siglo XX, la mayor parte habían logrado mantener el status de productores independientes. Para sostener este sitial, fue medular el óptimo conocimiento que habían desarrollado sobre el sistema de producción mixto que a lo largo de décadas habían aprendido a utilizar, el cual les permitía extraer de sus posesiones el producto para su mantenimiento, mientras coqueteaban con un mercado que se insinuaba cada vez más promisorio. Paradójicamente, el nuevo tipo de desarrollo que muchos 
de estos trabajadores avizoraban en la expansión de los mercados y por el que consciente o inconscientemente venían trabajando, implicaba atentar directamente contra el tipo de estrategia productiva que les había dado la vitalidad suficiente para subsistir durante decenios.

\section{Condicionantes históricos del proceso de transformación agrícola: 1955-1980}

Tanto las manifestaciones del cambio en la estructura geopolítica de postguerra y del capitalismo a nivel mundial, como los acontecimientos políticos que se desarrollaron en Costa Rica a mediados del siglo XX, influyeron para que se modificara la composición del Estado costarricense y se diera un viraje en sus objetivos particulares. ${ }^{13}$ En esta nación, la Guerra Civil de 1948 permitió el acceso al poder de nuevos sectores sociales cuya propuesta política, caracterizada grosso modo por sus planteamientos reformistas, contempló el establecimiento de nuevos ejes de acumulación y una ingerencia más activa en el modo en que se configuraban las bases de la estructura económica, así como en las relaciones político-sociales.

Siguiendo la tendencia impulsada por las nuevas perspectivas capitalistas después de 1949, el Estado costarricense se abocó a impulsar una política económica que creara las condiciones necesarias para reorientar el proceso de acumulación y, a nivel social, buscó una estrategia redistributiva que armonizara los intereses de clase y garantizara la reproducción de la fuerza de trabajo. Para crear un escenario que permitieran implantar una modo de desarrollo basado en la diversificación económica, donde la industria sustituyera paulatinamente a la agroexportación como eje de la economía, era necesario gestionar un proceso paralelo de modernización y diversificación de las actividades agropecuarias, que funcionaran como el sustento económico del proyecto. Esto implicaba incorporar nuevas áreas y actividades productivas con miras a la 
exportación, renovar el sector agrícola y asignarle otras funciones tales como la atención de la demanda de alimentos y materias primas a nivel interno. Es así como, a partir de la década de 1950, se produjo una importante transformación del agro costarricense.

Como se puede apreciar, al redefinirse el modelo agroexportador tradicional la inversión privada y del sector público se convirtieron en motores de desarrollo, lo cual nos permite deslindar algunos aspectos fundamentales para la cabal intelección del proceso. Por ejemplo, resulta evidente que a partir de este momento el Estado buscó una mayor cobertura con la creación de instituciones autónomas cuyo papel se inclinaba a ejecutar tareas específicas en los campos económico y social. En lo relacionado propiamente al agro, en el año de 1949 se funda el Consejo Nacional de la Producción (CNP), como institución que asumió la obligación de regular los precios de los productos agrícolas y desarrollar planes de modernización productiva y aplicación de nuevas tecnologías. En el aspecto financiero fue fundamental el papel del Banco Nacional de Costa Rica (BNCR) y en lo tocante al apoyo hacia la pequeña y mediana propiedad destacó, a partir de 1961, el Instituto de Tierras y Colonización (ITCO). Con este modelo los grupos locales se beneficiaron a través de su vinculación con el Estado, lo cual se manifestó claramente en el creciente desarrollo de las actividades del sector agroindustrial.

A partir de este punto, la coloración del proceso adoptaba nuevos tonos y las transformaciones analizadas no tardaron en tener un impacto preciso en el campo, pues las relaciones de producción capitalista se extenderían a todo el territorio complementando la idea de unidad nacional buscada por los socialdemócratas. La característica más sobresaliente del período fue el desarrollo in crescendo de la producción de mercancías en todo el país, lo que permitió el cumplimiento de objetivos como el aumento de las exportaciones, la ampliación del mercado interno y una mayor integración económica de la nación. 
La zona de estudio no estaría al margen de los cambios políticos y económicos que se dieron a partir de la década de 1950. Esto indicaba que la influencia de los factores externos encontró eco en un contexto donde existían circunstancias socioeconómicas propicias que posibilitaron la transformación de las condiciones existentes. Además, eran señal inequívoca de que había cristalizado en la zona un grupo más o menos homogéneo de actores sociales que, al contar con ventajas comparativas para vincularse exitosamente al mercado nacional e internacional, identificaban el nuevo proyecto con sus propios intereses y, por lo tanto, se encontraron en disposición de asumir y enfrentar los retos que imponían el nuevo plan de desarrollo. Para el caso de Pérez Zeledón, en un período menor a veinte años a partir de 1955, el número de las unidades productivas existentes se incrementó ampliamente. El crecimiento demográfico y el paulatino agotamiento de las tierras disponibles propiciaron la fragmentación de la propiedad, el aumento del número de fincas y la contracción del tamaño promedio de las unidades productivas. Por otra parte, el incremento del área agrícola profundizó los patrones del uso de la tierra y originó, entre 1955 y 1963, un significativo aumento de los sectores de pastos (55\%) y de las áreas utilizadas como tierras de labranza para el establecimiento de cultivos anuales (72\%). Empero, si algo fue notable durante esta etapa, fue la ampliación de los espacios destinados a la producción de cultivos permanentes, cuyas áreas se multiplicaron hasta en un 131 por ciento. Dicho crecimiento fue guiado, sobre todo, por la producción de café, el cual alcanzó su despegue definitivo gracias al impulso brindado por la instalación de los primeros beneficios privados en la región. Este primer momento de desarrollo coincidió con la política de desplazamiento de la producción a zonas marginales del país y se vio favorecida por una coyuntura de altos precios logrados por el producto en los mercados internacionales durante la década de los cincuenta. ${ }^{14}$

Esta incesante expansión de las actividades agropecuarias hizo que para 1963, la frontera 
agrícola del cantón hubiese declinado sensiblemente y en distritos como El General se hubiera agotado del todo. En el decenio siguiente, la poca superficie disponible ocasionó una mayor presión sobre el espacio, lo que elevaría el precio de la tierra y estrechó el límite de externo para el crecimiento de las unidades. La constante ampliación de las posibilidades comerciales, que impulsó a los productores a explotar de manera más eficiente las áreas productivas, dio como resultado que empezaran a experimentar la saturación del límite interior de sus propias fincas. Estos años serían fundamentales, pues fechan el momento en que muchos de los productores generaleños tuvieron que empezar a redefinir sus prioridades productivas considerando, por vez primera, el problema de la saturación del espacio.

Dado que la política agraria del Estado se orientó a la diversificación por medio del estímulo de cultivos tradicionales que mantuvieron su rentabilidad y de nuevos productos de exportación que gozaran de demanda internacional; entre 1963 y 1973 los patrones en el uso de la tierra empezaron a mostrar signos de cambio y en el distrito se empezó a privilegiar el crecimiento de las áreas destinadas a pastos y cultivos permanentes, en contraposición a las tierras de labranza que sufrieron una relativa pérdida de importancia. Este tipo de evolución en el uso del suelo evidenciaba que los productores, no sólo entendieron las implicaciones del nuevo modelo; sino que en un tiempo relativamente corto lo habían internalizado al punto de alterar radicalmente sus esquemas productivos tradicionales. En poco tiempo la producción se mercantilizó y todos los productores, aun los que conservaron -a distintas escalas- prácticas productivas propias del campesinado, debieron convertirse en productores de mercancías para poder adaptarse a un medio cada vez más competitivo. 


\section{Evolución de los sistemas de producción}

Las transformaciones en el ámbito productivo fueron posibles gracias a la conjunción de factores que posibilitaron el cambio agrícola; sin embargo, aunque el proceso contó con múltiples aristas, es claro que uno de los principales motores de desarrollo se ubicó en el despliegue dado en pro del fomento de una economía campesina libre, mercantil y diversificada. Como consecuencia, la década de los sesenta fue testigo de una mayor participación desde el ámbito estatal que, articulada por rutas institucionales, impulsó importantes esfuerzos para el desarrollo de la actividad agraria en la región. ${ }^{15}$

Dicho accionar también fue básico en la difusión de nuevas tecnologías productivas que contribuyeron al aumento de la producción y a la reversión de algunas limitantes naturales que presentaba la zona. Esta influencia significó que para el año de 1963, el 53 por ciento de las fincas utilizaran regularmente insumos como fertilizantes, lo que elevó marcadamente los índices de productividad en cultivos como el café, los granos y el tabaco. ${ }^{16}$ Por otra parte, la asesoría ayudó en la introducción de sistemas de control de hierbas y plagas, al manejo de técnicas de riego y la organización científica del espacio en los tipos de plantaciones que así lo requerían. Un elemento fundamental fue el mejoramiento genético llevado a cabo mediante el impulso de nuevas variedades; por ejemplo, en el caso del café, con la introducción del híbrido o hibrido tico (entre los que se pueden contar el "caturra", "villalobos" y "mundo novo"), que producían un mayor rendimiento y una mejor calidad del producto.

En lo referente al campo organizativo la década también fue prolífica y los esfuerzos de los generaleños habrían de encontrar expresión en la fundación de instituciones como Cooperativa de Caficultores de Pérez Zeledón de Responsabilidad Limitada (Cooperezeledón, 
R.L.) y, posteriormente, la Asociación de Productores de Tabaco de Pérez Zeledón; instituciones que aglutinaron a productores de diverso tipo en torno a un ideario de intereses comunes, consolidando un frente de oposición a las prácticas económicas, muchas veces abusivas, que hasta entonces habían ejercido los industrializadores, financistas y comercializadores privados.

El fruto de los avances obtenidos en el campo institucional, financiero, tecnológico y organizativo; así como el extraordinario comportamiento mostrado en el mercado por los productos tradicionales y por los nuevos productos de exportación, que hasta finales de la década de los setenta mantuvieron un crecimiento sostenido, no tardaría en evidenciarse y en menos de veinte años el cantón experimentó un aumento inédito en sus áreas de cultivo y en sus volúmenes de producción. En El General el cambio adquirió la forma de una reorganización de los sistemas productivos que se dio, sobre todo, atendiendo a cuestiones de disponibilidad de superficie y condiciones agroecológicas. Lo anterior por cuanto, pese al impulso logrado con la difusión tecnológica, la mayor parte de las producciones siguió fundamentándose más que nada en el incremento del área, lo que se reflejaría en la ampliación de las zonas de cultivo y en el inicio de un proceso de especialización agrícola, sobre todo a nivel de las pequeñas y medianas propiedades.

En los sectores de más antigua colonización, la descomposición de las propiedades originales tanto como debilitó a algunos productores, permitióla expansión de unidades de mediano y gran tamaño. En el caso de los pequeños productores, en vista de las pocas posibilidades con que contaban para ampliar sus áreas de trabajo, se inclinaron por la opción de la especialización productiva o la asociación de actividades específicas. En consecuencia, muchos minifundios se concentraron en la intensificación de las prácticas más rentables, restringiendo o eliminando por completo los tipos de producción que generaban menores ganancias. De tal modo, al tratar 
de aprovechar al máximo las condiciones existentes, hicieron un viraje para concentrarse en la siembra de café y granos, relegando parcial o completamente la producción de cultivos menores y la ganadería de pequeña escala.

Losmedianosproductores, queensutotalidadhabíanterminadoelprocesodeestablecimiento de sus unidades durante el período, también sufrieron importantes transformaciones. En primer término, algunas de estas fincas afrontaron procesos de fragmentación por herencia, pasando a convertirse en pequeñas propiedades que tendieron a la especialización productiva o fueron vendidas a productores en expansión; sin embargo, un grupo importante estuvo en capacidad de asimilar el cambio mediante la adecuación de sus unidades. A este conjunto pertenecieron productores que redujeron su carácter policultivista implementando sistemas de bicultivo que asociaba la producción de café-granos, café-caña, café-tabaco, caña-tacabo o granos-tabaco; también aquellos que emplearon sistemas de policultivo con cierta restricción en la asociación de actividades, que tomaron la forma de sistemas de producción de café-granos-caña-tabaco. Asimismo, funcionaron sistemas de policultivo-ganadería en que se combinaban de distintas maneras el café, los granos, la caña de azúcar y el tabaco, con la ganadería de doble propósito.

Con el énfasis puesto en la producción de mercancías destinadas al mercado, que en la mayoría de los casos empezaban a requerir de ciertos estándares de calidad y rendimiento, los factores agroecológicos empezaron a tener un mayor peso dentro de la lógica productiva. En consecuencia, para las unidades de medianas dimensiones fue cada vez más importante definir sus sistemas considerando las ventajas y limitantes con las que se enfrentaban. De acuerdo a esto, aunque en la mayoría de las fincas hubo una ampliación de las áreas de café; se mantuvo la caña y aumentó la producción de tabaco, mientras declinaban los cultivos anuales en favor de la ganadería. Por tal motivo, los sistemas ubicados en las terrazas del Río General, aun cuando 
presentaban patrones productivos muy similares a las unidades del fondo de valle, dadas sus características agroecológicas, favorables a la asociación café-caña, café-tabaco, caña-tabaco o café-caña-tabaco, mostraron una mayor tendencia a especializarse en dichos cultivos y al desarrollo de la ganadería de doble propósito.

La mayor parte de los grandes productores del fondo de valle y especialmente de las terrazas del Río General, que también habían avanzado considerablemente en el proceso de constitución de sus unidades, durante esta etapa empezaron a aprovechar al máximo sus ventajas comparativas inclinándose por un cambio tan cuantitativo como cualitativo; es decir, mediante la máxima ampliación de las superficies en uso, apostaron por el fortalecimiento de los productos que comercialmente mostraron más fortaleza. En la mayoría de estas unidades se privilegió el desarrollo de las áreas destinadas a la producción de café y de potreros para el desarrollo de una actividad ganadera que enfatizaba en la cría de animales para la producción de carne, auge que en el segundo de los casos suscitaría la aparición de una tendencia hacia la potrerización. Por su parte, la producción de caña de azúcar y tabaco, con un pausado pero constante crecimiento, se mantuvieron como opciones productivas de importancia; mientras que el cultivo de granos (especialmente de maíz) se siguió desarrollando como actividad adjunta pero en declive, que ayudaba a completar los calendarios de trabajo.

En el pie de monte la división de la propiedad favoreció, más que al surgimiento de minifundios, a la ampliación territorial de algunas unidades de mediana extensión especializadas en la producción cafetalera que; sin embargo, no llegaron a convertirse en unidades grandes. En estas unidades medianas se privilegió la ampliación del área de cultivos permanentes y la ganadería de doble propósito, con una mayor inclinación a la producción lechera. Aunque el aumento de la producción se habría originado principalmente en las zonas del fondo de valle, 
las terrazas del Río General y el pie de monte, durante este período también podemos apreciar como se van sumando a la actividad productiva ciertos espacios de las laderas empinadas de la zona suroccidental de la Cordillera de Talamanca. En estos sectores de reciente explotación los productores se dedicaron, sobre todo, a la producción café y ganado de doble propósito. Entre tanto, la región montañosa de la Cordillera de Talamanca se mantenía sin reportar la presencia de actividad de ningún tipo.

Si excluimos al cultivo cafetalero, que se había convertido en una constante productiva en las unidades del distrito y analizamos por separado el comportamiento de las distintas producciones tenemos que en el caso de los granos, la producción de arroz fue eliminada por completo pues ya no resultaba rentable, ni siquiera a nivel de autoconsumo, en vista de que aparecieron regiones en otras partes del país especializadas en su cultivo, frente a las cuales era imposible competir. La producción de frijoles se fue restringiendo a las pequeñas y medianas unidades de las terrazas del Río General y el pie de monte; mientras el maíz, aunque no mostró un gran desarrollo, se mantuvo como uno de los cultivos más generalizados entre las unidades productivas, mostrando un especial dominio en el fondo de valle.

La caña de azúcar se sostuvo, hasta inicios de la década de los setenta, como un cultivo asociado que en muchas de las fincas prosperaba temerosamente, a causa de la falta de infraestructura adecuada para su explotación a gran escala y dadas las patentes dificultades que existían para su comercialización. Las posesiones que mantuvieron este tipo de actividad fueron, sobre todo, las medianas y grandes unidades que poseían trapiches propios, las cuales continuaron con el patrón tradicional de producción de dulce que ubicaban en mercados extraregionales, especialmente en la Zona de los Santos o la Depresión Central. Por su parte, las unidades que no contaban con equipo para el procesamiento tendieron a abandonar esta práctica productiva en 
vista de que el alquiler de instalaciones y el transporte reducían considerablemente los márgenes de rentabilidad. Sin embargo, de 1972 en adelante, momento en que inicia el proyecto para establecer un ingenio en el distrito, la actividad experimentaría un giro definitivo, proceso que dio con su total industrialización.

La ganadería, cuya práctica fue abandonada casi por completo en los minifundios, creció en las fincas de mediano tamaño, especialmente a partir de una producción de doble propósito que seguía manteniendo cierto vínculo con el autoabastecimiento de la unidad. Distinta fue la forma en que se desarrolló en las grandes unidades, las cuales ampliaron sus extensiones de potrero para dar cabida a la especialización productiva de animales para carne. En este caso en particular, muchas de los sistemas que poseían grandes extensiones llegaron, incluso, a privilegiarla por sobre el café, pues se trataba de un tipo de producción que por su extensividad no requería de tanta inversión en trabajo y, en consecuencia, favorecía la reducción de costos.

Un caso interesante de considerar en la evolución de las unidades de mediano y gran tamaño, especialmente de aquellas que contaban con superficies explotables en la vera de los ríos General y Peñas Blancas, fue el renovado desarrollo que adquirió la producción tabacalera. Si bien este producto tenía alguna trayectoria en el valle, no es sino a partir de finales de los cincuenta y principios de los sesenta, con la creación de la Junta de Defensa del Tabaco, que algunas de estas unidades iniciaron la firma de contratos con empresas como la Republic Tobacco Co., afiliada a la British American Tobacoo con sede en Londres; y con la Tabacalera Costarricense, vinculada a la Philip Morris Int. de New York. Mediante la firma de este tipo de acuerdos algunas de estas unidades se beneficiaron del cultivo, al punto de integrarse durante la década de los sesenta y los setentas, como una de las actividades que aportaba mayor cantidad de ingresos a las fincas. Además, es importante mencionar que la vinculación a las firmas tabacaleras 
facilitó a las fincas productoras convertirse en receptoras de la transferencia tecnológica que, mediante los Departamentos de Agricultura de las empresas y de la labor que en este campo desempeñaba el Ministerio de Agricultura, a través de convenios con entidades internacionales, fueron desarrollados en aspectos como el mejoramiento del equipo y las técnicas de producción, conservación del suelo y otros.

Como podemos apreciar, los cambios en los sistemas productivos del distrito estuvieron influidos directamente por las transformaciones que impulsó el nuevo modelo económico en favor del agro. Fundamentados en los productos agrícolas para la exportación, pasaron a convertirse en el eje de la organización productiva al interior de las unidades, y los productores de todo tipo se aprovecharon de la coyuntura para capitalizar en su favor las facilidades de técnicas, organizativas, de crédito e inversión que habían sido puestas a su alcance, articulando así sistemas de nuevo tipo que pudieran responder a las demandas del mercado. En este proceso, las nuevas decisiones tomadas por los productores estaban relacionadas con las condiciones agroecológicas, con la rentabilidad económica de los cultivos y, en buena medida, con el tipo de desarrollo que en términos de infraestructura hubiese alcanzado cada una de las zonas productivas. Sin embargo, sería un error considerar que la evolución agrícola experimentada en el distrito y, particularmente, el cambio sufrido por los distintos tipos de unidades de producción fue un proceso impulsado únicamente por eventos externos que sólo influyeron a nivel de ordenamiento de los sistemas de producción. Esto, porque si algo es claro, fue la amplia participación desarrollada por los productores, cuyo apoyo al nuevo proyecto económico facilitó la incorporación de formas y técnicas productivas que fueron de meridiana importancia para que las propuestas a nivel macro permearan la naturaleza misma de las unidades productivas hasta originar un cambio en su carácter. 


\section{Conclusiones}

Durante la década de 1950, habiéndose superado casi por completo la fase de colonización agrícola, es posible asegurar que El General era una región que todavía se encontraba en pleno proceso de establecimiento de unidades productivas. Pese a los contrastes entre productores, es posible determinar que en términos generales las condiciones de la zona permitieron alcanzar una gran autosuficiencia, aun antes del despegue comercial producido por el establecimiento de vías de comunicación. Este factor se convertiría en un elemento clave para la exitosa inserción del distrito en el mercado nacional, pues la autosostenibilidad alcanzada dio margen a los productores para realizar el tránsito hacia una etapa de relaciones comerciales más profundas, sin llegar a poner en juego el diseño base de la forma de vida que habían venido desarrollado.

Las dos décadas y media que se marcan entre 1955 y 1980 fueron en su conjunto una etapa de cambios profundos en la vida del país. Las transformaciones planteadas no tardaron en tener un impacto decisivo en el mundo rural, pues a partir de ese momento la situación cambió radicalmente; siendo la características más sobresalientes el desarrollo de la producción generalizada de mercancías, lo que permitió concretar los objetivos de la política económica socialdemócrata. En consecuencia, a partir de 1950 se produjo una importante transformación del agro; cambio posibilitado por la adición de factores externos e internos que hicieron factible la modernización del agro, en cuyo desarrollo fue fundamental la cobertura estatal. La influencia de dichos estímulos rápidamente se combinó con las aspiraciones económicas de los productores por integrarse al mercado y en poco tiempo el espacio en que reinaban los sistemas de producción mixta para el autoconsumo, rápidamente fue dominado por un esquema económico que se basaba en relaciones de producción con el acento puesto en los vínculos con el mercado. Ahora el concepto de rentabilidad y máximo aprovechamiento de las ventajas comparativas eran, 
para un creciente número de fincas, los factores básicos de su lógica productiva. Este renovada perspectiva hizo variar el carácter agrario del distrito, propiciando la especialización por sobre aquellos mosaicos productivos desordenados pero diversos. Así, aunque se trató de una de las etapas de mayor crecimiento que se hayan registrado en la región; es imposible dejar de percibir que el proceso no dejaba de guardar cierta épica, en tanto involucraba una evidente tensión dialéctica al encubrir un cambio fundamental en la forma en que los agricultores se relacionaban con el campo. El proceso tendría, sin embargo, una pronta resolución y para el final de la etapa, era claro que la ruta de desarrollo a que fue impulsada la agricultura de la zona, acabó con aquel modelo económico autocentrado que habían fraguado los generaleños durante decenios.

\section{Notas}

\section{(Endnotes)}

1 Carlos R. Rodríguez. Tierra de labriegos: Los campesinos en Costa Rica desde 1950 (San José, Costa Rica: FLACSO, 1993), 26-29.

Para una información más detallada se puede consultar: Norman Durán Barrantes. Evolución de los sistemas productivos y relaciones de poder entre los agentes sociales que conforman la cadena productiva de la caña de azúcar en el distrito de El General, Pérez Zeledón, 1950-2000 (Tesis. Heredia, Costa Rica, para optar al grado de Magister Scientiae del Posgrado en Historia Aplicada con Mención en Estudios Agrarios, Universidad Nacional, 2006).

3 De la Dirección General de Estadística y Censos fueron analizados: DGEC. Censo Agropecuario de 1950 (San José, Costa Rica, 1952). DGEC. Censo Agropecuario de 1955 (San José, Costa Rica, 1956). DGEC. Censo Agropecuario de 1963 (San José, Costa Rica, 1965). DGEC. Censo Agropecuario de 1973 (San José, Costa Rica, 1974). DGEC. Censo Agropecuario de 1984 (San José, Costa Rica, 1986).

4 Norman Durán Barrantes. "La ocupación del espacio geográfico y el desarrollo de los sistemas de producción agrícola en el distrito de El General, Pérez Zeledón, entre la segunda mitad del siglo XIX y la primera mitad del siglo XX". Revista de Historia (Costa Rica) no 50-51, (julio-diciembre, 2005).

5 Para 1955 Pérez Zeledón era una de las regiones con más superficie forestal explotada. Fue la zona del 
territorio nacional donde se produjeron más carretadas de leña $(20$ 784), ocupó el tercer lugar en la producción de carbón (17663 sacos), el tercer lugar en producción de postes para cerca, (82 795 unidades) y sexto lugar en la producción de "trozas" o tucas (2 532621 pulgadas madereras).

6 Originalmente la actividad tabacalera fue desarrollada hasta por un 50 por ciento de los colonos como una actividad económica alternativa que se ubicaba al margen de las normas legales de la época.

7 La cría de ganado porcino durante las primeras tres décadas del siglo XX estuvo presente hasta en un 40 por ciento de las unidades productivas. Junto al autoconsumo, la venta de "chanchos" fue una tipo de intercambio basado en la venta de animales en pie a comerciantes de la Depresión Central.

8 Punto destacable era el elevado número de bueyes existentes en el distrito, lo cual es prueba de la poca difusión de maquinaria y automotores.

9 Como ejemplo, en 1954 la producción de queso alcanzó un total de 71 quintales anuales.

10 Adicionalmente, el 80.2 por ciento de las fincas poseían explotaciones de aves de corral y panales para la producción de miel de abeja, los que producían anualmente cerca de 55 galones del producto.

11 El sistema de producción se entiende aquí como el "conjunto estructurado de producciones vegetales y animales, establecido por un productor para garantizar la reproducción de su explotación; resultado de la combinación de sus medios de producción y de la fuerza de trabajo disponible en su entorno socioeconómico". Arnault Villaret. El enfoque sistémico aplicado al análisis del medio agrícola (San José, Costa Rica: PRADEM/CICDA, 1994).

12 El umbral de reproducción se estableció en 1500 colones anuales por productor, calculando una labor promedio de 6 jornadas semanales, con un salario de 5 colones diarios. Dicho cálculo también encontró fundamento en los testimonios de productores ubicados en el Censo Agropecuario de 1955.

13 En el contexto internacional esto coincidió con los proyectos de integración regional como la fundación de la CEPAL, la Alianza para el Progreso (ALPRO), el Mercado Común Centroamericano (MCCA) y la creación de organismos internacionales de ayuda entre los que se podrían contar el FMI, el BID y el AID; todos elementos fundamentales de la nueva articulación capitalista en América Latina, como producto de la redefinición de la geopolítica norteamericana hacia los países del Tercer Mundo. La gran mayoría de estas iniciativas establecían 
Indexaciones: Repositorio de Revistas UCR, DIALNET, Latindex, REDALYC Directorio y recolector de recursos digitales del Ministerio de Cultura de España, Directory of Open Access Journals. Diálogos Revista Electrónica de Historia ISSN 1409-469X. Número especial 2008. Dirección web: http://historia.fcs.ucr.ac.cr/dialogos.htm

como punto medular la promoción de programas agrarios que ayudaran a una distribución más equitativa del ingreso y que, al avanzar en la diversificación de las economías periféricas, redujeran la profunda dependencia existente con respecto al comercio exterior. Mayra Achío y Ana Escalante. Azúcar y política en Costa Rica (San José, Costa Rica, Editorial Costa Rica, 1985), 57-58.

14 Este desplazamiento, además de la ampliación del área de cultivo a nivel nacional permitía, gracias a las características agroecológicas de la zona, obtener una cosecha diferenciada con respecto a la Depresión Central y con ello, la creación de una demanda específica que mejorara el nivel de rentabilidad para el producto. Para más detalles: Jenny Liberoff y Johnny Mora. Raices, actores sociales y devenir histórico de una cooperativa agroindustrial. CoopeAgri El General R.L (Pérez Zeledón, San José, CoopeAgri R.L., 1993). caso del Instituto de Defensa del Café (1933) y de la banca, mediante la actividad del Departamento de Cooperativas y el Sistema de Juntas Rurales de Crédito. El ICAFE, con un rol de primer orden en la actividad cafetalera y potestades para incursionar en las más diversas actividades de este rublo. Junto a dichas instituciones se crearon una serie de entidades como el Consejo Nacional de Producción (1956) y el Instituto de Tierras y Colonización (1962), con el fin de favorecer a los productores agrícolas.

16 Por ejemplo, la ampliación de los rendimientos en el café resultó significativa, pues mientras en las fincas sin fertilizantes se lograba una producción de 7.5 fanegas por manzana, en las que aplicaban la nueva tecnología se incrementaba a 18 fanegas por manzana. 